\title{
Glycaemic Control among Patients with Diabetes in Primary Care Clinics in Jamaica, 1995 and 2012
}

\author{
MA Harris ${ }^{1}, \mathrm{~K}^{\mathrm{James}}{ }^{1}$, NK Waldron ${ }^{2}$, TS Ferguson ${ }^{3}$, JP Figueroa ${ }^{1}$
}

\begin{abstract}
Objective: To compare the quality of care received by patients with diabetes in public primary care clinics in 2012 with that reported in 1995.

Methods: Patient records were audited at six randomly selected Type III health centres in the South East Health Region of Jamaica. The 2012 audit data were compared with published data from a similar audit conducted in 1995. Quality of care measures included timely screening tests and counselling of the patients. Fasting and postprandial glucose tests were used to assess glycaemic control.

Results: Two hundred and forty-two patient records were analysed in 2012, and 185 in 1995. In 2012, $88 \%$ of patients were weighed within the last year compared with $43 \%$ in 1995 . Advice on physical activity increased from $1 \%$ to $60 \%$ and on dietary practices from $6 \%$ to $79 \%$. No patient had done the $H B A_{I C}$ in 1995 compared to $38 \%$ in 2012. In 1995, 66\% had blood glucose measured at a laboratory during the last year while in 2012, 60\% had a laboratory test and $90 \%$ were tested at the clinic by glucometer. Blood pressure control increased from 19\% in 1995 to $41 \%$ in $2012(\mathrm{p}<0.001)$. Poor glucose control was recorded among 61\% of patients in 1995 compared with 68\% in 2012.

Conclusions: There was no improvement in glycaemic control. Health providers and patients must work together to improve patient outcomes. This will involve closer patient monitoring, treatment intensification where indicated, and the adoption of lifestyle practices that can lead to better control.
\end{abstract}

Keywords: Clinical audit, diabetes, hypertension, Jamaica, primary care

WIMJ Open 2014; 1 (3): 99

\section{INTRODUCTION}

Diabetes mellitus continues to be a major public health problem globally and across the Caribbean (1-7). This is manifested by the high and rising prevalence of diabetes mellitus (DM) in the Caribbean $(1,2)$. The trend is consistent with projections for the Latin America and Caribbean region (LAC) which are projected to show an increase of up to $148 \%$ for the 2000 to 2030 period. $(7,8)$. The economic burden within the Caribbean region is also increasing with direct and indirect costs estimated to be US\$1120 per person per year which translates to US $\$ 209 \mathrm{M}$ or $2.7 \%$ of gross domestic product (GDP) in Jamaica (9-11).

Studies have been conducted to review and assess the level of care and the outcome among patients with diabetes

From: ${ }^{1}$ Department of Community Health and Psychiatry, Faculty of Medical Sciences, ${ }^{2}$ Mona Ageing and Wellness Centre, Faculty of Medical Sciences and ${ }^{3}$ Tropical Medicine Research Institute (Epidemiology Research Unit), The University of the West Indies, Kingston 7, Jamaica.

Correspondence: Dr MA Harris, Department of Community Health and Psychiatry, Faculty of Medical Sciences, The University of the West Indies, Kingston 7, Jamaica. E-mail: michelle.harris06@uwimona.edu.jm
$(12,13)$. One study conducted in 1995 at three different clinic settings in Jamaica found that only $40 \%$ of patients had satisfactory blood glucose control (12). A similar study done in Trinidad and Tobago, Barbados and Tortola, found that $50 \%$ of the patients had good blood glucose control. In both of these studies, very few patients were advised on diet, exercise or other non-pharmacological measures of control (13). In an effort to improve patient care, guidelines have been published nationally and regionally that address the management of diabetes (14-17).

The objective of this study was to assess the quality of care and glycaemic control among patients with diabetes mellitus treated at public primary healthcare clinics in the South East Health Region of Jamaica and to compare the current findings with those of the 1995 study.

\section{SUBJECTS AND METHODS}

This study was conducted as the baseline audit of an intervention trial to improve the management of cardiovascular (CVD) risk factors including diabetes mellitus within the South East Health Region of Jamaica. The audit was conducted between November and December of 2012 at six 
public primary care Type III health centres. The health centres studied were randomly selected from 22 eligible health centres. Type III health centres provide a broad range of medical services including family health, curative (acute and chronic illnesses), sexual and reproductive health and mental health services. A health centre with a pre-existing diabetes care intervention and those located more than 60 minutes by road from the Kingston metropolitan area were excluded. The results of this audit were compared with the published results of an audit that was conducted in 1995 by Wilks et al (12).

The audit was based on process and outcome indicators of quality of patient care as set out in the Ministry of Health $(\mathrm{MOH}) 2007$ diabetes treatment guidelines $(14,15)$. The process indicators included fasting blood glucose done within the last year, blood pressure and weight monitoring at last visit, body mass index (BMI) ever recorded and evidence of ever being counselled on adherence to medications, on physical exercise and dietary practices. The outcome measures included blood pressure and fasting blood glucose measurements.

The sample size was estimated to be 240 based on a formula provided by Diggle et al (18) for binary outcomes, a type 1 error probability of 0.05 , power of 0.8 , two measurements per participant, an adjustment for the effect of clustering (design effect $=1.06$ ) and a possible item nonresponse rate of $20 \%$. The sample was increased to 250 participants each from the intervention and non-intervention sites in order to allow for subgroup analysis.

The medical records audited were of patients 18 years or older, who attended for at least 18 months and who were diagnosed with any of the following: hypertension, diabetes mellitus, dyslipidaemia, stroke, coronary heart disease (including angina and myocardial infarction), congestive cardiac failure and peripheral arterial disease. The medical records of patients who were acutely ill were excluded. Each health centre was visited on the day of their chronic disease clinic and every second registered patient, if eligible, was recruited. The number recruited from each health centre was proportional to the total number of patients with chronic diseases seen at that health centre during 2011. The patients' names were recorded on a pre-coded form and assigned a research code-number. The lead researcher kept the list of names confidentially. Ethical approval was received from the Ethics Committees of the University Hospital of the West Indies/University of the West Indies/Faculty of Medical Sciences and the South East Regional Health Authority.

A field manual was developed and used to train the three research assistants. The data were entered, cleaned and analysed using the Statistical Package for the Social Sciences (SPSS) version 17. Poor glucose control was defined in the 1995 study as fasting blood glucose $\geq 8 \mathrm{mmol} / \mathrm{L}$ or random or postprandial glucose $\geq 10 \mathrm{mmol} / \mathrm{L}$ and elevated blood pressure (BP) was defined as $\mathrm{BP} \geq 140 / 90 \mathrm{mmHg}$. For the purpose of the comparison, similar cut points were applied to the 2012 data. $P$-values $<0.05$ were deemed to be statistically significant.

\section{RESULTS}

Characteristics of the patients whose charts were audited and comparison of process measures, screening and outcomes for 2012 and 1995 are shown in Table 1. Of the 242 patient

Table 1: Comparison of cases and processes of care in 1995 and 2012

\begin{tabular}{|c|c|c|c|}
\hline & 1995 & 2012 & $p$-value \\
\hline \multicolumn{4}{|l|}{ Cases } \\
\hline Number & 185 & 242 & \\
\hline Female, n (\%) & $160(86)$ & $152(63)$ & $<0.001$ \\
\hline Median age (IQR) (years) & $63(54-70)$ & $64(55-72)$ & - \\
\hline Median years of follow-up (IQR) & $6.3(3.5-9.0)$ & $4(3-15)$ & - \\
\hline On treatment for hypertension, $\mathrm{n}(\%)$ & $132(71)$ & $208(86)$ & 0.001 \\
\hline \multicolumn{4}{|l|}{ Processes of care in last 12 months, $n(\%)$} \\
\hline Weight recorded $(\mathrm{kg})$ & $79(43)$ & $214(88)$ & $<0.001$ \\
\hline Height (ever recorded) (m) & $4(2)$ & $82(34)$ & $<0.001$ \\
\hline Advised on physical activity & $1(1)$ & $146(60)$ & $<0.001$ \\
\hline Advice on dietary practices & $11(6)$ & $191(79)$ & $<0.001$ \\
\hline Advice on adherence to medications & $\mathrm{n} / \mathrm{a}$ & $201(83)$ & - \\
\hline \multicolumn{4}{|l|}{ Screenings in last 12 months, $\mathrm{n}(\%)$} \\
\hline Blood glucose tests done at a lab* & $123(66)$ & $146(60)$ & 0.096 \\
\hline Blood pressure & $182(98)$ & $217(90)$ & 0.003 \\
\hline Urine protein & $145(78)$ & $162(67)$ & 0.005 \\
\hline Fundoscopy & 0 & $4(2)$ & - \\
\hline Electrocardiogram (ECG) (ever done) & $\mathrm{n} / \mathrm{a}$ & $165(68)$ & - \\
\hline \multicolumn{4}{|l|}{ Outcome measures, n (\%) } \\
\hline Poor glucose control & $110 / 180(61)$ & $100 / 146(68)$ & 0.362 \\
\hline Blood pressure controlled & $25 / 132(19)$ & $86 / 208(41)$ & $<0.001$ \\
\hline
\end{tabular}

*These were tests done in the laboratory on fasting or postprandial blood samples 
dockets reviewed, $86 \%$ were diagnosed and on treatment for hypertension in 2012 compared with $71 \%$ in 1995 . Significantly more patients had their weight and height recorded, more electrocardiograms (ECGs) were done and more patients received advice on physical activity and dietary practices in 2012 when compared with 1995. Screening of blood glucose and blood pressure were similar. Since $\mathrm{HbA}_{1 \mathrm{C}}$ was not available in the public health service, no patients had this test done in 1995.

Table 2 shows the use of various pharmacological agents for the treatment of diabetes mellitus and hypertension

Table 2: $\quad$ Main treatments used by patients with diabetes in 1995 and 2012

\begin{tabular}{lccc}
\hline & $\mathbf{1 9 9 5}$ & $\mathbf{2 0 1 2}$ & $\boldsymbol{p}$-value \\
& $\mathbf{n}(\mathbf{\%})$ & $\mathbf{n}(\mathbf{\%})$ & \\
\hline Anti-diabetic medications & $(\mathbf{n}=\mathbf{1 8 5})$ & $\mathbf{( n = 2 4 2 )}$ & \\
Insulin & $12(7)$ & $51(21)$ & $<0.001$ \\
Metformin alone & $1(1)$ & $88(36)$ & $<0.001$ \\
Sulphonylurea alone & $87(47)$ & $13(5)$ & $<0.001$ \\
Metformin and sulphonlyurea & $76(41)$ & $59(24)$ & $<0.001$ \\
& & & \\
Antihypertensive medications & $(\mathbf{n}=\mathbf{1 3 2})$ & $(\mathbf{n}=\mathbf{2 0 8})$ & \\
Diuretics & $9(7)$ & $120(58)$ & $<0.001$ \\
Calcium channel blockers & $1(1)$ & $62(30)$ & $<0.001$ \\
Methyldopa & $60(46)$ & $6(3)$ & $<0.001$ \\
Reserpine & $70(53)$ & $8(4)$ & $<0.001$ \\
ACE inhibitors & 0 & $133(64)$ & - \\
Angiotensin receptor blockers & 0 & $21(10)$ & - \\
& & & \\
\hline
\end{tabular}

in 2012 and 1995. Insulin use was increased in 2012 compared to 1995 . Significantly more patients were prescribed a sulphonylurea in 1995 while metformin was more common in 2012. Reserpine and methyldopa were commonly used for hypertension in 1995 while angiotensin-converting enzyme (ACE) inhibitors, diuretics and angiotensin receptor blockers were more common in 2012.

There was no improvement in blood glucose control. Binary logistic regression showed that age, gender and use of insulin did not affect diabetes control but years since being diagnosed with diabetes was a significant predictor of control in 2012. As years since diagnosis increased, patients were less likely to be controlled ( $p=0.034)$. The 1995 study reported that poor blood glucose control was not affected by gender, age, duration of follow-up or use of insulin.

There was better blood pressure control among the patients in 2012 but neither age, gender, years since being diagnosed with diabetes nor achieving diabetes control were predictors of blood pressure control. The 1995 study reported that neither age, duration of follow-up nor gender affected blood pressure control.

\section{DISCUSSION}

We have found that while there was an improvement in the process of care measures in 2012 compared to 1995 and more patients achieved blood pressure control, there was no improvement in blood glucose control.
Our findings are consistent with two other studies done in the region that failed to show improvement in diabetes care among public primary care patients. In Barbados, there was no change in blood glucose control among public patients (22) while in Trinidad and Tobago, there was no improvement in blood glucose or blood pressure control (23).

Newer antihypertensive medications such as ACEinhibitors and calcium channel blockers that were not available in 1995 were commonly used by public sector patients in 2012. This difference in medications could have influenced the better control of hypertension that was observed. The increase in patients using insulin in 2012 may be an indication of more severe disease or a greater willingness to use insulin by both patients and their doctors.

The use of routine data from patient charts rather than taking standardized measurements is a limitation of the study. However, the blood tests were conducted at licensed laboratories that are monitored for quality control. Another limitation is that the BMIs of the patients were not available for the 1995 data to allow for comparison. Given the increasing levels of obesity in the general population, this could have influenced the failure to observe an improvement in blood glucose control.

\section{CONCLUSIONS}

There was improvement in the screening, monitoring and counselling of patients in 2012 compared to 1995. This did not translate to improved blood glucose control. The use of newer classes of antihypertensive medications may have impacted positively on blood pressure control. Health providers and patients must work together to achieve adequate glycaemic control. This will involve closer patient monitoring, treatment intensification where indicated, and the adoption of lifestyle practices that can lead to better control.

\section{ACKNOWLEDGEMENTS}

The authors thank the staff of the South East Regional Health Authority for facilitating this study. Thanks also to Dr Novie Younger-Coleman for statistical advice. This study was funded by a Caribbean Health Research Council/Caribbean Public Health Agency grant.

\section{REFERENCES}

1. Wilks R, Younger N, Tulloch-Reid M, McFarlane S, Francis D. National Healthy Lifestyle Survey II, 2007. Kingston: Epidemiology Research Unit, TMRI; 2008. Available from: http://www.mona. uwi.edu/reports/health/JHLSII_final_may09.pdf

2. Hennis A, Wu S, Nemesure B, Li X, Kesec MC. Diabetes in a Caribbean population: epidemiological profile and implications. Int $\mathrm{J}$ Epidemiol 2002; 31: 234-9.

3. Hennis A, Fraser HS. Diabetes in the English-speaking Caribbean. Pan Am J Pub Health 2004; 15: 90-3.

4. Latchan Z, Seereeram R, Kamalodeen A, Sanchez S, Deonarine U, Sinanan R et al. TRAQ-D (Trinidad Risk Assessment Questionnaire for Type 2 Diabetes Mellitus): a cheap, reliable, non-invasive screening tool for diabetes. Br J Diabetes Vasc Dis 2010; 10: 187-92. doi: $10.1177 / 1474651410366553$. 
5. Grievink L, Alberts JF, O'Niel J, Gerstenbluth I. Waist circumference as a measurement of obesity in the Netherlands Antilles; associations with hypertension and diabetes mellitus. Eur J Clin Nutr 2004; 58:1159-65. doi: 10.1038/sj.ejcn.1601944.

6. Ward E, Grant A. Epidemiological profile of selected health conditions and services in Jamaica 1990-2002. Kingston: Health Promotion and Protection Division, Ministry of Health; 2005.

7. Ferguson TS, Tullock-Reid MK, Wilks RJ. The epidemiology of diabetes mellitus in Jamaica and the Caribbean: a historical review. West Indian Med J 2010; 59: 259.

8. Wild S, Roglic G, Green A, Sicree R, King H. Global prevalence of diabetes: estimates for the year 2000 and projections for 2030. Diabetes Care 2004; 27: 1047-53.

9. Caribbean Commission on Health and Development. Report of the Caribbean Commission on Health and Development. Washington, DC: PAHO and Georgetown: Caribbean Community Secretariat; 2006.

10. Abdulkadri A, Cunningham-Myrie C, Forrester T. Economic burden of diabetes and hypertension in CARICOM states. Soc Econ Stud 2009; 58: $175-97$.

11. Barcelo A, Aedo C, Rajpathak S, Robles S. The cost of diabetes in Latin America and the Caribbean. Bull World Health Organ 2003; 81: 19-27.

12. Wilks RJ, Sargeant LA, Gulliford MC, Reid ME, Forrester TE. Management of diabetes mellitus in three settings in Jamaica. Pan Am J Public Health 2001; 9: 65-71.

13. Gulliford MC, Alert CV, Mahabir D, Ariyanayagam-Baksh SM, Fraser HS, Picou DI. Diabetes care in middle income countries: a Caribbean case study. Diabet Med 1996; 13: 574-81.

14. Ministry of Health, Jamaica. Guidelines for the management of hypertension. Kingston: Ministry of Health; 2007a.

15. Ministry of Health, Jamaica. Guidelines for the management of diabetes. Kingston: Ministry of Health; 2007b.

16. Caribbean Health Research Council. Managing diabetes in primary care in the Caribbean. St Augustine: Caribbean Health Research Council; 2006.
17. Caribbean Health Research Council. Managing hypertension in primary care in the Caribbean. St Augustine: Caribbean Health Research Council; 2007.

18. Diggle P, Heagerty P, Kung-Yee L, Zeger S. Analysis of longitudinal data. New York: Oxford University Press; 2002: 30-31.

19. Eldemire-Shearer D, James K, Morris C, Holder-Nevins D, Laws H, Harris M. Chronic disease and ageing in the Caribbean: opportunities knock at the door. West Indian Med J 2011; 60: 471-7.

20. American Diabetes Association. Peripheral arterial disease in people with diabetes (Consensus Statement). Diabetes Care 2003; 26: 3333 41.

21. Gulliford MC, Mahabir D. A five-year evaluation of intervention in diabetes care in Trinidad and Tobago. Diabet Med 1999; 16: 939-45.

22. Adams OP, Carter AO. Are primary care practitioners in Barbados following diabetes guidelines? A chart audit with comparison between public and private care sectors. BMC Res Notes 2011; 4: 199. doi: 10.1186/1756-0500-4-199.

23. Mahabir D, Gulliford MC. Changing patterns of primary care for diabetes in Trinidad and Tobago over 10 years. Diabet Med 2005; 22: $619-24$.

Submitted 07 Apr 2014

Accepted 06 Jun 2014

Published 10 Nov 2014

Online: http://www.mona.uwi.edu/wimjopen/article/1604

(C) Harris et al 2014

This is an open access article made freely available under Creative Commons Attribution 4.0 International (CC BY 4.0). Users are free to share, copy and adapt this work as long as the copyright holder (author) is appropriately and correctly credited. See http://creativecommons. org/licences/by/4.0/deed.en_us for more information. 